\title{
Smartvote.lu: usage and impact of the first VAA in Luxembourg
}

\author{
Patrick Dumont and Raphaël Kies* \\ University of Luxembourg (IPSE), \\ Research Program on European Governance, \\ Route de Diekirch, B.P. 2 L-7201 Walferdange, Luxembourg \\ Email: patrick.dumont@uni.lu \\ Email: raphael.kies@uni.lu \\ *Corresponding author
}

\begin{abstract}
This paper analyses the electoral usage and impact of smartvote.lu, the first Voting Advice Application (VAA) introduced in Luxembourg at the occasion of the 2009 national elections. We devise a series of expectations regarding the use and impact of the instrument and provide both descriptive and multivariate analyses on data drawn from a 'classical' post-electoral survey representative of all voters. Despite the need for studies using this type of empirical material and multivariate methods to draw valid lessons on the determinants of VAA use and the potential electoral impact of these devices, such a combination is still rare in the nascent literature on VAAs, and arguably allows us to make a valuable contribution to it. Our main finding is that the most educated are more likely to use the VAAs but less likely to be influenced by it.
\end{abstract}

Keywords: voting advice application; Smartvote; e-democracy; Luxembourg; elections; electoral behaviour.

Reference to this paper should be made as follows: Dumont, P. and Kies, R. (2012) 'Smartvote.lu: usage and impact of the first VAA in Luxembourg', Int. J. Electronic Governance, Vol. 5, Nos. 3/4, pp.388-410.

Biographical notes: Patrick Dumont is a researcher at the University of Luxembourg. His main research interests include coalition theory, political elites, parties, party systems, and Europeanisation processes on which he has published in international journals such as the European Journal of Political Research, European Union Politics, Journal of European Public Policy, Public Choice and West European Politics. He recently co-edited The Selection of Ministers in Europe. Hiring and Firing (Routledge, 2009) with Keith Dowding, and Puzzles of Government Formation: Coalition Theory and Deviant Cases (Routledge, 2011) with Rudy B. Andeweg and Lieven De Winter. He is also the co-editor, with Keith Dowding, of the Routledge Research in Social and Political Elites book series.

Raphaël Kies is a researcher at the University of Luxembourg. His main research interests are citizen's participation, electoral studies and theories of democracy with a focus on e-democracy and deliberative democracies. Recent publications are Promises and Limits of Web-Deliberation (Palgrave, 2010) and the co-edited forthcoming book Is Europe Listening to Us? Successes and Failures of EU Citizen Consultations with Patricia Nanz (Ashgate, 2013). 


\section{Introduction}

With the exponential number of Voting Advice Applications (VAA) implemented worldwide, academics become increasingly interested in seeing whether these tools are actually widely used by the public and whether VAAs may have a concrete impact on electoral outcomes. Research on these issues is still at a preliminary phase, displaying contradictory results and limited methods of assessment. The main contribution of this article is to provide a first multivariate analysis, based on a representative post-electoral survey, of the factors influencing both the usage and impact of the VAA. This study confirms several findings that were observed in other research and points to a larger trend connecting the usage and the impact of the VAAs, namely that the most educated are more likely to use a VAA but less likely to be influenced by it. This finding partly confirms the theory elaborated by Zaller (1992) with regard to the positive relation between the political competence of citizens and their electoral usage of mass media.

The analysis focuses on the website smartvote.lu (SV), the first VAA ever experienced in Luxembourg during the 2009 national elections. The Internet platform implemented was the twin sister of the Swiss VAA Smartvote. As the Swiss counterpart, Luxembourg's VAA aimed at matching the preferences of the voters with the ones of the competing candidates and parties on the basis of a common questionnaire. The questionnaire was drafted by a team of researchers from the University of Luxembourg and contained 36 statements related to the party manifestos, fundamental values of the parties, as well as policy issues that emerged during the preceding legislative terms and other potentially controversial campaign topics. The findings are drawn from the data gathered through a 'classical' post-electoral survey also elaborated by the University of Luxembourg in the context of the national electoral study.

In the first section of this article we present the theoretical background as well as the main findings provided by similar studies on VAAs implemented in other countries. We then specify a list of hypotheses regarding the usage and impact of SV. The following section discusses the reliability of the post-electoral survey data on which our empirical analyses are based. Finally, the last sections present and discuss our findings.

\section{Theoretical and contextual background}

Since VAAs are new campaigning instruments on which research has just begun, there are to date no theories perfectly geared to explain and predict the usage and impact of VAAs. This section refers to theories on electoral behaviour and mass media, for which we argue that the scope of applicability can be extended to the VAAs. It further identifies potential explanatory factors derived from the characteristics of the Luxembourgish political system, and from the findings of the few existing studies on VAA usage and impact in other political contexts.

\subsection{Theoretical background}

A first useful research field for explaining the usage and impact of VAAs is the process of partisan dealignment. Since the end of the 1960s, electoral research has shown that changes in social structures brought about by economic and technological changes have led to a process of 'dealignment' vis-à-vis traditional political and social organisations, 
no longer perceived as representing the interests of voters. The numerical decline of traditional party clienteles (blue-collar workers, petty bourgeoisie, farmers) in favour of new white-collar middle class with no clear party loyalty, the convergence of life-styles, the process of secularisation and individualisation in our western societies have tremendously reduced vote choices based on structural cleavages such as class and religion and as an expression of a collective identity. Several scholars diagnose that this has led to the falling electoral turnout and party membership in most established democracies (Dalton and Wattenberg, 2000), the rise of electoral volatility (especially since the 1990s, see Gallagher et al., 2006), as well as different forms of split-ticket voting and personal vote (see Dalton and Wattenberg, 2000; Dumont et al., 2006, 2010 for the case of Luxembourg). This evolution indicates that voters increasingly base their electoral choice on specific issues and on individual political leaders and candidates instead of on loyalty to a party's core ideology. We suggest that this process of dealignment and the increasing importance gained by voting issues and candidate preferences and personality should favor the use of VAAs, given that the main goal of these instruments is precisely to provide party- and candidate-centred information on electoral pledges and on political relevant issues for voters.

The potential large usage and impact of VAAs can also be derived from the theory on heuristic cues that states that although the sophistication of voters is on the rise due to the democratisation of education, increasing complexities in public policy making (due to the growth of state, the rise of supra- and sub-national governance levels or the constraints on and interdependencies of political decisions in a globalised economy) have led to a growing cognitive distance between voters and political elites, leading to a perceived transparency deficit with regard to the political process. Voters generally do not possess complete information over candidates, and, due to a lack of motivation or of competence, prefer not to invest in costly search for information and instead rely on cognitive shortcuts, such as party cues, to guide their electoral choice (see Downs, 1957). The danger of such a strategy is that political elites are the driving force in the process of opinion formation during electoral campaigns: according to Zaller (1992), it is indeed because they are badly informed that citizens have to rely on the cues and recommendations supplied by political elites themselves. VAAs can contribute to lower several cognitive barriers originally identified by Downs in order to become a better informed voter. First, the procurement costs - corresponding to the costs of gathering, selecting and transmitting information - are almost annihilated by the VAAs in so far as they gather, select and transmit relevant information on electoral issues and indicate in a user-friendly way the position of parties and candidates on these same issues. Second, VAAs have the potential to simplify and improve the analysis process - corresponding to the costs of undertaking a factual analysis of data - by providing synthetic factual data on all the issues that are considered relevant for the elections. Lastly, VAAs simplify the evaluative process - corresponding to the costs of relating data or factual analysis to specific goals - by providing the possibility to easily compare personal preferences on important issues with the ones of parties and candidates. The importance of these VAA characteristics in the context of the new media is confirmed by the experimental research undertaken by Lupia and Philpot (2005), which reveals that viewing a website is more likely to affect a citizen's political interest if (s)he perceives the site has certain attributes (e.g., is nonpartisan, offers unique content, and provides information efficiently). One of the main conclusions of these authors is that "viewer's perception of a site's effectiveness and efficiency is critical. Given the massive competition for a viewer's attention - from 
other websites and from life in general - viewers are more likely to attend to sites that they perceive as providing interesting information effectively and efficiently" (Lupia and Philpot, 2005, p.1125). In sum, this analysis suggests that the informative value of the tool combined with its accessibility and user-friendliness should encourage not only a relevant number of voters to use it but also to be influenced by it. The present article aims at identifying the conditions under which voters' needs for 'rational shortcuts', such as those provided by VAAs, are greater as well as those in which these instruments have an effect on voting behaviour.

As far as the range and intensity of the electoral impact is concerned, the literature focusing on the impact of mass media on electoral behaviour converges on the fact that this remains rather modest. Klapper (1960) already argued that the political impact of the media was likely to be attenuated for a variety of reasons summarised by Carmines and Huckfeldt (1996, p.239): “(1) citizens are not sufficiently attentive to be affected; (2) conflicting and intermittent messages tend to cancel out one other; (3) Individual level process - selective attention and retention based on pre-existing political predispositions - tend to distort media messages and hence nullify their effects; (4) Any message that does leak through to the individual has been processed through patterns of social interaction and communication". It should however be noted that this theory concerns the impact of the mass media and for this reason cannot be said to account for the characteristics of the Internet and in particular of the VAAs. In fact, VAAs strongly differ from this description of the mass media for at least two reasons. The first concerns the attention of their users in so far as the usage of VAAs requires an active and attentive participation in order to read, understand, take a position on the different items and to make sense of the way they are positioned themselves vis-à-vis the parties, the candidates and on the different political dimensions. The second main difference is that the VAA does not provide conflicting and intermittent messages. On the basis of the same set of preferences a given VAA will always indicate the same outcomes. ${ }^{1}$ Both these differences suggest that the potential impact of the instrument is likely to be on average higher than the one of the mass media even if VAAs may have no impact on the other factors indicated earlier, namely pre-existing political predispositions as well as social interactions and communications.

Investigations on citizens' predispositions to be influenced by the media tend to show that education plays a prominent role in the search for and processing of new information (Tichenor et al., 1970; Robinson and Levy, 1986). The rationale behind this is that better educated people have a greater propensity to learn, to gather and value political information and to be socialised in a context where this information is valorised and discussed. It is however clear that education is only a rough indicator of people's receptivity to news, since within education strata there is considerable variance in attentiveness to public affairs (Price and Zaller, 1993, p.138). What appears to be the most efficient indicator of an effective reception of the incoming political information is pre-existing political knowledge (Delli Carpini and Keeter, 1993; Zaller, 1992; Price and Zaller, 1993). Zaller (1992) argues that politically aware voters are more likely to expose themselves to new information while at the same time they are least likely to be persuaded by any kind of information that is inconsistent with their prior beliefs. In our empirical analysis, due to the unavailability of measures of pre-existing political knowledge we limit our investigation to the role of education, political interest and the level of media consumption on the probability of people's VAA usage and impact on the vote. Assuming that these indicators provide a good approximation of political 
knowledge, we expect to observe that well educated voters, interested voters, and heavy consumers of electoral information are greater VAA users but also less likely to be influenced by such an instrument. A third predisposition that should be considered in the context of the new media is age. Most of the empirical studies at the national (Dumont et al., 2010, pp.90-96) and European level (Kies, 2010, chap 3) indicate that young generations are much more likely to use the internet as a source of information and as a means of political action (ex: Facebook, e-petitioning, web-forums, etc.). As a consequence, we expect that the use and impact of VAAs is also related to age. The influence could be all the more strong that the characteristics of VAAs (fun, interactive, user-friendly) are particularly well adapted to the informative needs of younger generations.

\subsection{Contextual background}

Although Smartvote was introduced in 2009 for the first time in the Grand Duchy, we expected the participation to be rather large for a series of context-specific reasons. First, nowadays the digital divide has dramatically shrunk and should not have prevented many citizens to use the instrument. Indeed, according to Eurostat, in 2009 no less than $87 \%$ of Luxembourg's population had access to the internet. Second, Luxembourg has a highly candidate-centered Proportional Representation electoral system close to the one in use in Switzerland that not only allows voters to choose either for a list vote or preferential votes, but also permits to distribute the latter across party lists, what is referred to as 'inter-party panachage'. Voters may even award two votes to their preferred candidates (cumulative voting) and have as many votes to distribute as there are seats to be filled in each of the four constituencies of the country used for national elections. Since 2004 an absolute majority of voters casts preferential votes and the proportion of inter-party panachage has doubled from 1979 to 2009, now concerning about 4 voters out of 10 (Dumont et al., 2010). Third, contrary to Finland or Switzerland which are also wellknown for their candidate-centered systems, in Luxembourg voting is, in addition, compulsory for nationals between 18 and 75 of age. The combination of these two features of the electoral system assumes that voters have sufficient knowledge to decide whether their best choice should be a list vote, a personalised vote for some candidates of the same list or to cast a vote for candidates of different lists, whereas in reality information or interest is clearly lacking for a large proportion of the population with voting rights. According to the 2009 post-electoral survey, less than half $(42 \%)$ of the preferential voters knew all the candidates they voted for (Dumont et al., 2010, p.89). In any case, there is a high potential for heavy VAA usage, either on the part of sophisticated voters wishing to get their choice confirmed by the online tool or by undecided or uninformed voters looking for easy access information on parties and candidates to guide their vote because they are legally obliged to go to the polls. Finally, an incentive for a rather widespread public participation was the broad acceptance of the tool by political actors. All parties in competition throughout the country accepted to give their official position and more than half of the candidates (236 out of a total of 452) accepted to be part of the "game". ${ }^{2}$ This favourable acceptance of the tool was in part triggered by the large visibility that SV acquired in the main media both off- and online. 


\section{Working hypotheses}

From this theoretical and contextual review we elaborated several working hypotheses that are complemented with hypotheses generated from findings observed in other similar studies, particularly in Switzerland where the same VAA has been implemented already since 2003. The objective is to observe whether these findings are replicated (or not) in the case of Luxembourg and to establish evaluative standards that are adapted to our national context.

\subsection{Hypotheses on usage}

We expect the usage of smartvote.lu (SV) to be rather widespread because of its informative potential (see heuristic cue theory), the process of individualisation of vote, and because it appears to be particularly well adapted to the electoral characteristics of Luxembourg. A valid standard for evaluating the level of usage of SV in Luxembourg is to compare it with the one of SV in Switzerland in so far as both instruments are the same and the electoral systems share many similarities. According to the Swiss data, SV was used by around $2.5 \%$ of the population (with voting right) for the 2003 federal election and around $10 \%$ for the 2007 elections (Fivaz, 2008; Ladner et al., 2008). ${ }^{3}$

Concerning the characteristics of the users we expect, as suggested in the previous section and as reported in several other studies, that the use of SV is positively related with the age the level of education and the political interest (in general and for the electoral campaign in particular) of citizens as well as their global level of electoral information consumption.

HU1: Young citizens are greater users of SV than older citizens

HU2: High educated citizens are greater users of SV than low educated citizens

HU3: Citizens with high interest in politics are greater users of SV than citizens with low interest in politics

HU4: Citizens with high interest in the political campaign are greater users of SV than citizens with low interest in the political campaign

HU5: Citizens who are high consumers of electoral information are greater users of SV than low consumers of electoral information

Our next hypotheses are related to the level of complexity of the vote. We argue that the complexity of the vote, as measured by the size of the electoral constituency (with a greater number of MPs to be elected and therefore votes to be distributed making the act of voting more complex) and previous electoral choice (with citizens having cast a preferential vote in the previous election more likely to issue such a kind of vote again rather than cast a simple list vote), may constitute an incentive to use SV.

HU6: Citizens voting in large constituencies are greater users of $S V$ than citizens voting in small constituencies

$\mathrm{HU7}$ : Citizens who privilege preferential voting are greater users of SV than citizens who privilege list voting 
In addition, we anticipate on the basis of other similar studies (Ruusuvirta, 2010; Marschall and Schmidt, 2010; Fivaz and Nadig, 2010) that SV users tend to be more leftwing than the average population. In order to explain the role of political values such as subjective positions on a left-right scale, Wall et al. (2009) suggest that respondents who locate themselves on the left side of the political spectrum tend to be less conservative in terms of sources of political information and therefore more open to test this new online instrument.

\section{HU8: Left-wing citizens are greater users of SV than right-wing citizens}

\subsection{Hypotheses on electoral impact}

As far as the electoral impact of VAAs is concerned, existing studies present different and often contradictory findings. A very strong impact has been observed in Switzerland where for the 2007 federal elections two-thirds of smart-users (67\%) declared that the voting recommendations they received from the online tool had an impact on their electoral decision and on the quality of their information on candidates and parties (Fivaz, 2008; Ladner et al., 2010). Similarly, one third of VAA users in Finland declared that this had at least some importance in their electoral choice. Finally, $40 \%$ of the German Wahl-O-Mat users said that this had an impact on their electoral choice for 2005 federal elections (Ruusuvirta and Rosema, 2009). Conversely, a limited impact was observed for the Flemish VAA based on the "Do the vote test" TV show. A sample of 7,500 users indicated that more than $90 \%$ of the panelists who watched the TV show or got personal voting advice from the website denied that the VAA affected their vote (Walgrave et al., 2008).

In our case, we expect the impact to be rather important because, as mentioned in the preceding section, SV provides a particularly valuable informative tool in a context where preferential voting is high and vote is compulsory. We however expect a more limited impact than the one observed during the 2007 federal elections in Switzerland because SV was implemented for the first time in Luxembourg in 2009. Due to the novelty of the instrument, many users in Luxembourg may have lacked trust in the advices provided compared to the Swiss context where SV has become a mainstream device. Another reason for expecting a more modest impact is that the question aimed at measuring it differs. In Switzerland, a general question asking whether SV had any kind of impact on the vote was asked, while in the case of Luxembourg, the impact on the vote was divided into several categories reflecting different types of impact (see below). This implies that the Swiss users could report a perceived impact in a much broader way than the Luxembourgish users.

We expect most of the factors identified earlier as potentially having a role in citizens' decision to use SV to also determine the impact of this VAA on their vote, albeit for some in the opposite direction as the one hypothesised for usage. First, concerning age, we would expect such an impact for younger SV users, as the young are generally less attached to any party, less informed about politics and therefore probably more easily influenced during the political campaign. Contrary to their expected positive effect on usage, we hypothesise education, electoral information consumption, and interest in politics (both in politics in general and in the campaign in particular) to be negatively related to VAA impact. In relation to the theory of Zaller we expect that well educated and politically interested voters are better able to sort out between various sources of 
information through which they form their opinions, and therefore to relativise - or indeed criticise - the 'advice' given by the online tool. In addition, we would expect these types of respondents to be reluctant to acknowledge in a survey that they have been influenced by a VAA, and to therefore under-report its impact.

HI1: Young citizens are more influenced in their electoral choice by SV than older citizens

HI2: High educated citizens are less influenced in their electoral choice by SV than low educated citizens

HI3: Citizens with high interest in politics are less influenced in their electoral choice by $S V$ than citizens with low interest in politics

HI4: Citizens with high interest in the political campaign are less influenced in their electoral choice by SV than citizens with low interest in the political campaign

HI5: Citizens who are high consumers of electoral information are less influenced in their electoral choice by SV than low consumers of electoral information

As for usage, we test whether the complexity of the vote is related to the electoral impact of SV. The complexity of voting choice is measured, on the one hand, by the propensity of issuing a preferential vote for individual candidates rather than casting a list vote and, on the other hand, by the size of the electoral constituency which determines the number of candidates to be elected.

HI6: Citizens voting in large constituencies are more influenced in their electoral choice by $S V$ than citizens voting in small constituencies

HI7: Citizens who privilege preferential voting are more influenced in their electoral choice than citizens who privilege list voting

\section{Methodology and data sources}

Most of the existing studies on the characteristics of VAA users and the potential role of the latter in electoral campaigns have so far been based on optional online questionnaires filled by the people who made use of the instrument. Those users are generally 'selfselected', that is they voluntarily respond to the questions of the survey when they are invited to do so, either when they registered to the VAA in order to get more services or by reacting to a pop-up window asking their help to improve the platform (the survey may be akin to an 'exit poll' one, taking place right after the use of the online tool or at a later stage, which can be post-electoral, if the user left a valid email address), without any sample selection made by the survey administrators. Scholars who could only rely on such means of data collection have addressed the issue of representativeness of the VAA user population by either aiming at a random selection of respondents or, more often, by simply checking the plausibility of their resulting distributions for some variables in comparison with studies of larger populations or findings from similar studies abroad. Such studies face a problem of available data to assess the real impact of these instruments, and more specifically a self-selection bias in the samples analysed (as clearly exposed by Vassil, 2011). 
In order to draw inferences regarding the determinants of VAA usage, we need a representative sample of both users and non-users. To date, only a few research teams had the opportunity to insert questions regarding VAA usage in large- $n$ surveys representative of the voting population such as those typically elaborated for national election studies. Among the studies which made use of such data, we find some that do not distinguish between VAAs (that may be of varying quality and enjoy different degrees of visibility) when several were made available to the voters in the electoral campaign (see an overview of Finnish results in Ruusuvirta, 2010) and others that did not provide for statistical analyses controlling for the effect of several factors that could influence the use or the impact of VAAs (see for instance Fivaz and Nadig, 2010 for Switzerland or Ruusuvirta and Rosema, 2009 for the Netherlands). In this article we aim therefore at providing one of the first multivariate statistical analyses of the determinants of VAA usage and potential impact on the vote, based on a dataset drawn from a 'classical' post-electoral survey representative of a whole voting population.

In this section we first discuss the reliability of our post-electoral survey data by comparing the latter with those collected through an 'exit'-type online questionnaire that SV users were invited to fill after they completed their profile. We then present the operationalisation of our dependent and independent variables and the method used to test our hypotheses.

\subsection{Data reliability}

In Luxembourg, citizens visiting the SV website were also invited to respond to an 'exit'type optional online questionnaire when they registered to the tool (in order to save and therefore easily retrieve their SV profile, send a summary of their results to friends etc.). The dataset built on this optional survey of registered users consists of 2,008 respondents, ${ }^{4}$ but is not the one on which we will base our empirical analyses in the following sections of this article. Rather, it is used in Table 1 to compare the distributions obtained through this type of survey that is typically used in the nascent VAA literature and the post-electoral survey dataset of Luxembourg's national election study. The latter consists of 1,267 respondents interviewed either by phone or by internet, the random sample being further weighted to be representative of Luxembourg's entire voting population.

We expect differences in distributions over a number of variables between the two datasets, due to the distinct methods of data collection. A self-selection process being at work for the SV online optional survey, it is very likely that the latter has attracted some 'elite' of the VAA users, in other words the typical young, male, well educated individual found in other studies using the same type of data. The characteristics of the SV registered users should therefore be exacerbated in comparison with what a random sample representative of the whole voting age population would reveal about VAA users. However, we also expect the two datasets to broadly share similar patterns with respect to the profile of SV users as compared with the overall population. A broad convergence in the distinguishing features of users would indeed further reinforce our confidence in the results of the more sophisticated empirical analyses of the following section on the determinants of VAA usage. 
Table 1 Socio-demographic characteristics of smart-users in the post-electoral survey and in the SV optional survey

\begin{tabular}{|c|c|c|c|c|c|}
\hline & $\begin{array}{l}\text { 1. General } \\
\text { post elect }\end{array}$ & $\begin{array}{l}\text { 2. SV users } \\
\text { post elect }\end{array}$ & $\begin{array}{l}\text { 3. SV registered } \\
\text { users }\end{array}$ & $\begin{array}{c}\text { Diff. } \\
2-1\end{array}$ & $\begin{array}{c}\text { Diff. } \\
3-1\end{array}$ \\
\hline $\operatorname{Sex}$ & (n:1267) & $(\mathrm{n}: 162)$ & $(\mathrm{n}: 1722)$ & & \\
\hline Female & 48.4 & 41.4 & 33.9 & -7.0 & -14.5 \\
\hline Male & 51.6 & 58.6 & 66.1 & 7.0 & 14.5 \\
\hline Age & $(\mathrm{n}: 1267)$ & $(\mathrm{n}: 161)$ & $(\mathrm{n}: 1756)$ & & \\
\hline $18-24$ & 10.7 & 19.3 & 18.5 & 8.5 & 7.7 \\
\hline $25-34$ & 13.9 & 27.3 & 32.9 & 13.4 & 19.0 \\
\hline $35-49$ & 26.7 & 21.7 & 31.0 & -5.0 & 4.3 \\
\hline $50-64$ & 24.1 & 23.6 & 15.1 & -0.5 & -9.0 \\
\hline 65-Highest & 24.6 & 8.1 & 2.3 & -16.5 & -22.3 \\
\hline Mean & 48.7 & 39.8 & 36.40 & -8.9 & -12.3 \\
\hline Electoral circumscription & (n:1267) & $(\mathrm{n}: 163)$ & (n:1507) & & \\
\hline Centre & 29.3 & 36.2 & 39.7 & 6.9 & 10.4 \\
\hline South & 40.4 & 37.4 & 33.6 & -3.0 & -6.8 \\
\hline North & 17.4 & 15.3 & 13.2 & -2.1 & -4.2 \\
\hline East & 12.9 & 11.0 & 13.5 & -1.8 & 0.6 \\
\hline Education & (n:1267) & $(\mathrm{n}: 154)$ & (n:1702) & & \\
\hline Primary school & 4.8 & 0.6 & 1.5 & -4.2 & -3.4 \\
\hline Secondary 1 st cycle & 16.0 & 5.8 & 9.1 & -10.2 & -6.9 \\
\hline Secondary 2 nd cycle & 38.8 & 24.0 & 27.3 & -14.8 & -11.5 \\
\hline $\begin{array}{l}\text { Higher edu }+1 \text { to }+3 \\
\text { years }\end{array}$ & 27.3 & 40.3 & 21.7 & 13.0 & -5.6 \\
\hline $\begin{array}{l}\text { Higher edu }+4 \text { years and } \\
\text { more }\end{array}$ & 13.0 & 29.2 & 40.4 & 16.2 & 27.4 \\
\hline
\end{tabular}

The comparison of columns 5 and 6 in Table 1 shows indeed a high degree of correspondence between the profiles of SV users across datasets generated through distinct methods, but also, as expected, that the online optional survey reinforces most of the differences that distinguish SV users from the overall voting-age population in the post-electoral survey. Compared to the profile of SV users according to the post-electoral survey, SV users who registered and responded to the optional survey are even more often male ( $+7.5 \%$ points), younger ( -3.4 years for their average age) and better educated $(+11.2 \%$ points declare having followed long university studies). This broad convergence between data drawn from different sources and the exacerbation of features of users in the SV online optional survey increases our confidence in the validity of our results in the following statistical analyses based on the post-electoral survey, as the effects found in the next sections of this article are likely to be conservatively measured. 


\subsection{Operationalisation and method}

Our first dependent variable is usage, coded as a dummy indicating whether a respondent to national election survey elaborated or not a profile on SV. The second dependent variable is impact and is also coded as a dummy even though the original variable had several categories specifying different kinds of impact. For the recoded variable we record an impact whenever users indicated any of these potential impacts: i) reinforcement of initial voting intention for candidate; ii) modification of initial voting intention for candidates, iii) reinforcement of initial voting intention for party list; iv) modification of initial voting intention for party list. For users answering 'no impact' we coded the variable as 0 . As mentioned earlier, this measure is different than the one used to assess SV impact in the Swiss context. It also aggregates reinforcement and change effects, which we would have studied separately if the number of users and therefore the number of cases for each category had been greater. In addition, our measure aggregates effects on both candidate and party choices. One should bear in mind that a change in candidate choice may not have a tremendous political meaning, as it may concern only one or a couple of candidates of a single party in constituencies where voters have up to 23 votes (in the South) to distribute. The decision to vote for another would arguably reflect a much greater change, and we therefore expect the political advices of SV to have influenced candidate choices more often than party choices. In the empirical section dedicated to the analysis of SV impact, we start by providing a descriptive analysis of our original variable distinguishing across types of impact. Given the limited number of users we nevertheless had to aggregate all kinds of self-reported effects of SV on the vote and build a dummy variable for our analysis of the determinants of SV impact, which we therefore consider here latu sensu, that is without distinguishing the different types of impact (parties vs. candidates) and the direction of the impact (change vs. confirmation). Given that both of our dependent variables are dummies we use logistic regression models to test the hypotheses presented earlier.

The independent variables included in these models are (see Appendicies A and B for a more detailed description of the data): 1) Age, for which we distinguished five categories from younger to older; 2) Education, that is also subdivided in five categories from lower to higher; 3 ) The electoral constituencies (South elects 23 MPs, Centre elects 21 MPs, North and East respectively elect 9 and 7 MPs); 4) Interest in politics in general, based on four categories from high to low; 5) Interest in the political campaign measured also based on four categories from high to low; 6) Media consumption, which cumulates the scores of three variables regarding traditional media consumption (radio, newspapers, television) when it comes to gathering electoral information. Note however that here lower values indicate heavier media consumption. We therefore expect a negative relationship between this variable and SV usage (with those more informed - indicated by lower values of the variable media consumption - being more likely to be SV users) and a positive one with SV impact (with those more informed being less likely to report SV impact); 7) Preferential vote in 2004, which distinguishes users who voted for individual candidates in 2004 from the ones who privileged a list vote in $2004 .{ }^{5} \mathrm{We}$ further include respondents' subjective left-right positioning, which locates them on a 10points left-right scale, from left to right, both in our analysis of SV usage where this variable is needed to test hypothesis $\mathrm{HU}$, and as a control variable in our study of SV impact. As is the case in most other studies, we further include gender as a control for both our analyses. 


\section{Findings for usage}

\subsection{Findings for general level of usage}

The proportion of SV users varies greatly according to the data considered. The 2009 post-electoral survey indicates that SV was used by $13 \%$ of the population while almost $60 \%$ of the respondents never heard about it. As argued earlier, these results should however be handled with care, considering the socio-demographic biases that electoral surveys in general suffer (lower educated people are less easy to reach and those uninterested in politics less likely to agree to respond to a time consuming survey), which are made greater if the survey is partly implemented through the internet, as was the case for Luxembourg's national election survey. ${ }^{6}$ Given this risk of overrepresentation of SV usage, we further evaluated this by counting users' sessions. This measurement assumes that each session corresponds to a unique user (Marschall and Schmidt, 2010; Fivaz and Nadig, 2010). This is therefore just another evaluation which can here fall prey to two main sources of error, one being the risk of over-representing SV users when a person elaborates several profiles at different times because this person is counted as a different user for each profile, the other being the risk of under-representation when different persons elaborate a profile during a same user session because they are counted as a unique user. Overall then, even though we may suspect the former phenomenon to prevail, the fact that each bias would cause effects in opposite directions allows us to assess the proportion of users with this alternative and widely employed measure. In Luxembourg, 15,100 sessions were recorded during the campaign period. This figure would correspond to about $7 \%$ of the electoral population (a bit less if one considers the number of voters supposed to cast a vote and a bit more if one considers the number of people who actually came to vote) having visited and elaborated an SV profile, which is about half of the proportion arrived at through the post electoral survey. We expected a certain level of over-reporting with the latter kind of data, which does not however prevent us from undertaking a reliable analysis of the determinants of usage.

\subsection{Statistical analysis}

We now turn to a statistical model in order to assess which factors have an actual effect on the probability of using SV at the occasion of the 2009 elections when controlled for alternative explanatory variables. In the first model only socio-demographic variables are entered. The second model further includes variables regarding respondents' interest in politics, level of information, political values as measured by their subjective left-right position and previous voting behaviour. Since with models using dummies as dependent variables the relationship between variables is not assumed to be linear but logistic, assessing the impact of each independent variable is not straightforward, but we can learn from the significance and direction of the coefficients presented in the table. These are odds ratios (labelled as $\exp (B)$ ) for which values between 0 and 1 indicate in our case that the probability of being a SV user is smaller for the category at hand than for the reference category, whilst values higher than 1 indicate that this probability is greater than for the reference category. For instance in Model 1 of Table 1 and using the highest level of education as reference category, we see that respondents with any other (lower) level of education is less likely to be SV users than the better educated. For continuous variables these values indicate negative and positive relationships with the dependent 
variable respectively, for instance in Model 2 a coefficient below 1 as the one we get for left-right position indicates that left-wing voters (those who chose to locate themselves closer to the extreme left and therefore closer to 1 on the 10-points scale) are more likely to be SV users.

Table 2 Binary logistic regression models explaining SV usage - $(\exp (B))$

\begin{tabular}{|c|c|c|}
\hline & Model 1 & Model 2 \\
\hline \multicolumn{3}{|l|}{ Age (ref: 65 and more) } \\
\hline $18-24$ & $7.227 * *$ & $16.170 * *$ \\
\hline $25-34$ & $5.151 * *$ & $7.699 * *$ \\
\hline $35-49$ & $2.597 * *$ & $3.433 * *$ \\
\hline $50-64$ & $3.297 * *$ & $2.901 * *$ \\
\hline Sex (ref: male) & $0.602 * *$ & $0.582 *$ \\
\hline \multicolumn{3}{|c|}{ Education (ref: higher education $>3 y$ ) } \\
\hline primary school & $0.062 * *$ & 0.000 \\
\hline secondary 1 st cycle & $0.170 * *$ & $0.363^{*}$ \\
\hline secondary 2 nd cycle & $0.224 * *$ & $0.310^{* *}$ \\
\hline higher $(<3$ y) & $0.572 *$ & 0.796 \\
\hline \multicolumn{3}{|c|}{ Constituency (ref: South (23 MPs)) } \\
\hline East (7 MPs) & 0.950 & 0.945 \\
\hline North (9 MPs) & 1.132 & 1.102 \\
\hline Centre (21 MPs) & 1.230 & 1.258 \\
\hline \multicolumn{3}{|c|}{ Interest in politics (ref: not interested) } \\
\hline very interested & & 1.113 \\
\hline fairly interested & & 0.808 \\
\hline \multicolumn{3}{|c|}{ Interest in campaign (ref: not interested) } \\
\hline very interested & & 3.140 \\
\hline fairly interested & & 2.549 \\
\hline barely interested & & 1.754 \\
\hline Trad media consumption & & 0.874 \\
\hline Left-right position & & $0.857^{*}$ \\
\hline Preferential vote in 2004 & & 0.864 \\
\hline Constant & $0.151 * *$ & 0.220 \\
\hline Pseudo-R² (Nagelkerke) & 0.175 & 0.250 \\
\hline $\mathrm{N}$ included & 1152 & 757 \\
\hline
\end{tabular}

Several socio-demographic indicators included in Model 1 appear to predict SV usage. The clearest example is the age of the respondent. The effect is highly statistically significant for all the comparisons between the reference category (people aged 65 and over) and any other category, and this result is robust to the introduction of the variables on political interest, information, left-right position and previous voting behaviour in Model 2. The younger cohort can be up to 10 times (and more) more likely to be a SV 
user than aged respondents. The odds ratios tend to decrease linearly but we still have much lower chances of finding respondents from the oldest age category among SV users than for those between 50 and 64 of age. Our first hypothesis (HU1) regarding the effect of age is therefore clearly established. Education also has the effect we expected (HU2), with the reference category of respondents with a university degree (at least 3 years of higher education) being significantly and considerably more likely to use SV than any other category, if we leave aside the more limited higher education one in Model 2. Among socio-demographic indicators we also find the electoral constituency of the respondent, for which we hypothesised a greater propensity for using SV in larger constituencies given the higher level of complexity of the vote in these constituencies. What we find is that only voters from the East (the smallest constituency) are less likely to be users than those from the South (the largest one); those voting in both the North and Centre constituencies are however more likely to being smart-users compared to voters of the South, a result that - even though none of the coefficients show a significant relationship - contradicts our expectation (HU6). A potential explanation for this result is that the South, besides being the largest constituency, is also the one of the four which has traditionally been characterised by a vote more heavily determined entrenched social cleavages inherited by the region's industrial past (Dumont et al., 2006; 2010). We may therefore expect that incentives to look for electoral information will be reduced in such contexts, compared to the rural North, which despite being a small constituency is characterised by a much higher level of preferential votes and of inter-party panachage in particular, witnessing a much lower degree of ideologically-determined voting behaviour. The difference between South and Centre is even greater, with voters of the latter constituency being more eager to look for electoral information in a context where the vote is almost as complex (21 MPs to be elected compared to 23 in the South) but where the urban electorate living in and around the capital is displaying a lower degree of party attachment. Finally, let us note that the gender variable entered as a control in the two models has a significant effect, with women being about $40 \%$ less likely to use Luxembourg's VAA than men.

Our 'socio demographics-only' model reaches a Pseudo $\mathrm{R}^{2}$ of 0.175 , but our predictive capacity increases to 0.250 when we enter the other variables in Model 2. As Table 2 shows, this is not due to the expected significance of political interest as a predictor, as it turns out that in the case of Luxembourg this variable does not appear to have a significant effect when controlled for alternative factors. Interest in the current campaign comes much closer to significance and as expected the effect is positive (the more interest in the campaign, the greater the likelihood of using a VAA). This implies that our hypotheses are not confirmed with regard to the political interest $(\mathrm{HU} 3)$ in general and partly confirmed with regard to the interest in the political campaign (HU4). This difference that may be simply due to the fact that people more interested by the current electoral campaign reflect a more domestically-oriented political interest or even more temporary one such as for example people who just lost their job, or who became interested in elections because of some specific policies implemented by the incumbent government or radical propositions made by some parties in the campaign. People interested in the political campaign may also be more attentive to the production of electoral information and therefore to the introduction of new campaign instruments than people interested in politics in general. We also find that media consumption has a positive effect on the likelihood of using SV, with respondents who are more eager for 
political information being more likely to be SV users (recall that smaller values on that variable indicate a higher level of media consumption), even though this effect fails to reach statistical significance (HU5). Contrary to our expectation however, respondents who expressed a preferential vote in 2004 were not more likely to be SV users (HU7). This relationship is not significant but may indicate a phenomenon that we underestimated when devising our hypothesis. It may indeed be the case that a substantial proportion of preferential voters find that their vote is informed enough and do not need further indications to express a complex choice involving votes for specific candidates who may belong to different parties. Conversely, there may be a greater proportion of list voters than expected who are disposed to challenge their previous vote and face their predispositions to new information. Finally, Model 2 also includes the left-right subjective position of the respondent. As expected, and as shown in other contexts as well, we find that the more leftist the respondent the greater the chances (s)he will use the VAA (HU8).

\section{Findings for impact}

\subsection{General impact: descriptive analysis}

Almost one third (31\%) of SV users declared that SV had an impact on their vote $(n=$ 162). In the original question to which respondents were invited to answer the impact was subdivided into four categories. Concerning the impact on the choice of candidates, $10 \%$ considered that SV encouraged them to vote for candidates they did not plan to vote for while $7.6 \%$ said that SV reinforced their choice to vote for candidates they had planned to vote for. Concerning the impact on party only $3.6 \%$ said that SV encouraged them to vote for a different party, while $10 \%$ considered that SV reinforced their choice to vote of a party they had planned to vote for. As expected, we see that an impact in the form of a change of candidate voted for is much more likely than a change of party.

\subsection{Statistical analysis}

As for the analysis of the determinants of SV usage, we here run two models aimed at predicting SV impact on the vote of respondents, as reported by the latter. Given the much restricted number of observations (162 SV users) and the skewed distribution of several variables (such as age or education) within this sub-population, however, we do expect a lower level of predictive performance and number of significant relationships. As a matter of fact, we only find three statistically significant results in Model 1 made of only socio-demographic variables. The most interesting one regards education, which displays a significant effect (taking $p<0.1$ with this limited $n$ of 162) when comparing the odds of impact on the vote for respondents with long higher education and those with shorter higher education, with the latter being more likely to declare such an impact. The comparison between the category just below (people having completed only secondary school) and the category with university degree also came close to significance. Since we only had a few SV users with lower education we can conclude that education is indeed a determinant of VAA impact on the vote, with the better educated appearing more 
equipped to resist such an influence (H/2). Hence, results concerning education suggest that some determinants of usage of the instrument act as barriers against its influence on the behaviour of users. The second statistical relationship established concerns the constituency of the respondent (HI6). Here we expected a greater impact of SV in constituencies where voting choices are more complex, and therefore in particular those in which a higher number of candidates are running for elections. We already noted in the analysis of usage that a sociological or traditional voting behaviour argument could counteract than the mechanical (complexity of the vote) explanation, as the largest constituency (South) is also the one where the vote is still largely determined by longstanding party attachments and that a small constituency like the North is on the other hand well-known for its much more open voting behaviour (characterised by a high level of inter-party panachage). We indeed find that respondents from the North are much more likely to report an impact than those from the South. Long-standing differences in the determinants and structure of the vote in these two constituencies appear to play a role in the impact of SV on electoral choice as reported by voters. A closer inspection of the response categories used to report some impact indeed shows that North voters indicated that SV changed their mind or reinforced their preferences for specific candidates, thereby confirming that this result has to do with the particularly high propensity of preferential voting in that constituency. We observe as expected that older people are in general less likely to be influenced by SV (HI1) than younger ones but do not find any significant relationships. Gender does not either appear as a significant predictor of SV impact on the vote.

The inclusion of other variables in Model 2 does not increase our overall predictive capacity, showing that socio-demographic variables are the only ones considered in this study to have (for some) an effect on the impact of the Luxembourg VAA on voting behaviour. It however allows us to see that the (already not significant) relations find between SV impact and age or gender do not have stable effects. Whereas being a voter from the North constituency still makes one more likely to report an impact of SV than voters from the South, showing again that the significant effect found in Model 1 is due to the traditional voting behaviour of the constituency rather than the complexity of the vote (HI6), the significant result for education disappears with the introduction of the other variables (H/2). Political interest in general (H/3) and interest in the campaign (HI4) in particular prevent respondents from being influenced by SV, but in both cases the effect is not significant. As expected also, a higher level of media consumption plays the same role, as we see that those most informed are less likely to report an impact of the online instrument, but here again the effect is not significant (HI5). Finally, having expressed a preferential vote in the previous election reduces the chances of declaring having been influenced by SV, a result which runs counter our expectations (H/7). Even though the effect does not reach statistical significance, we indeed see here that list voters tended to report some kind of influence (recall that this may be a mere reinforcement of preferences) more often than preferential voters. Note that we included the subjective left-right position of the respondent as control variable in this model, allowing for greater comparability of findings across our analyses of the two dependent variables of interest, but the effect is not significant and minimal in scope. 
Table 3 Binary logistic regression models explaining SV impact on vote $-(\exp (B))$

\begin{tabular}{|c|c|c|}
\hline & Model 1 & Model 2 \\
\hline \multicolumn{3}{|l|}{ Age (ref: 65 and more) } \\
\hline $18-24$ & 1.533 & 0.870 \\
\hline $25-34$ & 0.917 & 1.228 \\
\hline $35-49$ & 1.275 & 0.968 \\
\hline $50-64$ & 1.116 & 1.609 \\
\hline Sex (ref: male) & 0.936 & 1.003 \\
\hline \multicolumn{3}{|c|}{ Education (ref: higher education $>3 y$ ) } \\
\hline primary school & - & - \\
\hline secondary 1 st cycle & 1.758 & 0.881 \\
\hline secondary 2 nd cycle & 1.913 & 2.647 \\
\hline $\operatorname{higher}(<3 \mathrm{y})$ & $2.230(*)$ & 1.921 \\
\hline \multicolumn{3}{|c|}{ Constituency (ref: South (23 MPs)) } \\
\hline East (7 MPs) & 0.733 & 0.847 \\
\hline North (9 MPs) & $3.350 *$ & $3.325(*)$ \\
\hline Centre (21 MPs) & 1.090 & 1.108 \\
\hline \multicolumn{3}{|c|}{ Interest in politics (ref: not interested) } \\
\hline very interested & & 0.683 \\
\hline fairly interested & & 1.075 \\
\hline \multicolumn{3}{|c|}{ Interest in campaign (ref: not interested) } \\
\hline very interested & & 0.543 \\
\hline fairly interested & & 0.343 \\
\hline barely interested & & 0.100 \\
\hline Trad media consumption & & 1.334 \\
\hline Left-right position & & 0.982 \\
\hline Preferential vote in 2004 & & 0.776 \\
\hline Constant & $0.184 *$ & 0.163 \\
\hline Pseudo-R ${ }^{2}$ (Nagelkerke) & 0.124 & 0.130 \\
\hline $\mathrm{N}$ included & 155 & 117 \\
\hline
\end{tabular}

\section{Discussion}

Smartvote.lu, the first VAA ever implemented in Luxembourg in 2009, turned out to be a powerful electoral tool, as evidenced by its widespread usage. We consider that this large success is due the utility and user-friendliness of the instrument, its large acceptance by parties and candidates, and by the peculiar electoral rules of the Grand-Duchy that combine compulsory voting and preferential voting. For the next legislative election of 2014, we expect SV to increasingly become a mainstream instrument due to the success of the instrument among the youngest generation and the increasing notoriety it should acquire among the numerous users who were not aware of its existence during the 2009 campaign. 
In line with other studies, our analysis of the determinants of SV usage shows that VAA users belong to the social elite. They are more likely than the average electoral population to be young, well-educated and to position themselves on the center-left side of the political spectrum. A high level of interest in the political campaign comes close to being a significant predictor of SV usage, whereas the direction of the hypothesised effect of political interest in general and of media consumption is verified in our empirical study but the relationships fail to be statistically significant. Contrary from what we expected, the complexity of the vote (preferential vs. list vote) and the number of candidates to be elected in the constituency - what we can refer to as the 'structural' components of the vote - did not constitute a strong incentive to use SV. Finally, the gender variable entered as a control has a significant effect, with women being less likely to use Luxembourg's VAA than men.

With regard to the electoral impact, we observed that almost one third of the users acknowledged some SV impact on their vote, either encouraging them to vote for candidates or parties they planned to vote for or leading them to vote for parties or for candidates they did not plan to vote for. Due to the limited amount of respondents for the different categories of impact, our preliminary statistical analysis focused on the general impact of SV, thereby aggregating confirmation and change of the voting intention, either for a party or for candidates. We find that education explains SV impact, with citizens who are highly educated being less likely to be influenced by SV, although the significance of this relationship vanishes in our most extensive model. A more robust effect is found for the electoral constituency of the respondent. Contrary to our expected mechanical effect (complexity of the vote), we see that it is rather the context-specific prevalence of social cleavages and party attachments that make a difference across constituencies. We observe in particular that voters from the North, which is traditionally the constituency with the highest level of preferential votes and inter-party panachage, reflecting a higher degree of party dealignment, are more likely to report an impact of SV on their vote than those from the South where ideology-driven party vote still prevail. Several other variables appear to affect the impact of SV in the direction predicted by our hypotheses. This was the case for high political interest (in general), high interest in the campaign and high level of media consumption which seem to prevent respondents from being influenced by SV, but these effects were not significant.

A general lesson that emerges from this analysis is that the theory of Zaller (1992) on the competence of voters could be to a certain extend applied to explain the use and impact of SV. Zaller observes that the more competent voters are the more likely they are to expose themselves to new information while at the same time they are least likely to be persuaded by any kind of information that is inconsistent with their prior beliefs. A similar trend could be observed for the SV users who are more likely to possess attributes characterising competent voters (well educated, interested in politics, strong consumers of information). Zaller's theory appears to be relevant, however to a lesser extent, to also explain the impact of SV, since these same characteristics appear to prevent voters to be influenced by SV.

A proper test of Zaller's theory would require the inclusion of questions enabling researchers to construct a 'competence index'. It would in addition require the use of a panel sample where respondents would be asked about their voting intention in a preelectoral survey and actual voting behaviour in a post-electoral survey. These are improvements we are envisaging for the next electoral study. Let us note that our 
understanding of the factors influencing the usage and, more significantly, impact of SV will also improve as a consequence of the expected increase of SV users. A greater number of SV users among survey respondents will allow us to increase the predictability power of our models on SV impact and crucially distinguish between types of impact ('confirmation' vs. 'change').

Finally, extending our discussion to the literature on VAAs in general, we should note that the expected increase in the number of VAA users through time will also change the composition of this group, making it a less homogenous 'elitist' sub-sample of the population. It will be interesting to see how this will change the level of observed impact of the online tool. On the one hand it could lead to a greater impact on the vote, as we saw in our research that the elite tends to be less effected by such voting advices. On the other hand, we may expect only a limited change in the impact of VAAs on the vote as lower educated citizens who are expected to be increasingly present among SV users also tend to have long-standing political loyalties, being influenced by their social milieu and/or determined by cleavages, and therefore less inclined to follow these advices. Our research indeed showed that the context-specific strength of cleavages and party attachments plays a role, with more dealigned electorates being more likely to report an impact of SV on their vote. Future studies will investigate whether changes in the sociological composition of the group of VAA users make a difference and whether a generalised trend toward party dealignment leads to a greater impact of such instruments.

\section{Acknowledgements}

This research was conducted in the context of the POLUX project funded by the Luxembourg's National Fund for Research (FNR). The authors wish to thank the journal's anonymous reviewers for their advices.

\section{References}

Carmines, E. and Huckfeldt, R. (1996) 'Political Behavior: an overview', in Goodin, R. and Klingelmann, H-D. (Eds): New Handbook of Political Science, Oxford University Press, Oxford, pp.223-254.

Dalton, R. and Wattenberg, M. (2000) Parties without Partisans: Political Change in Advanced Industrial Democracies, Oxford University Press, Oxford.

Delli Carpini, M. and Keeter, S. (1993) 'Measuring political knowledge: putting first things first', American Journal of Political Science, Vol. 37, No. 4, pp.1179-1206.

Downs, A. (1957) An Economic Theory of Democracy, Harper and Row, New York.

Dumont, P., Fehlen, F., Kies, R. and Poirier, P. (2006) Les élections législatives et européennes de 2004 au Grand-Duché de Luxembourg. Rapport élaboré pour la Chambre des Députés,: Service Central des Imprimés de l'Etat, Luxembourg.

Dumont, P., Kies, R., Spreitzer, A., Bozinis, M. and Poirier, P. (2010) Les élections législatives et européennes de 2009 au Grand-Duché de Luxembourg. Rapport élaboré pour la Chambre des Députés, Service de l'imprimerie de l'Etat, Luxembourg.

Fivaz, J. (2008) 'Impact of "smart-voting" on Political Participation', Paper presented at the Civic Education and Political Participation Workshop at the Université de Montréal, 17-19 June, Montreal, Canada. 
Fivaz, J. and Nadig, G. (2010) 'Impact of Voting Advice Applications (VAAs) on Voter Turnout and Their Potential Use for Civic Education', Policy and Internet, Vol. 2, No. 4.

Gallagher, M., Laver, M. and Mair, P. (2006) Representative Government in Modern Europe, 4th ed., McGraw-Hill, New York.

Kies, R. (2010) Promises and Limits of Web-deliberation, Palgrave, New York.

Klapper, J.T. (1960) The effects of Mass Communications, Free Press, New York.

Ladner, A., Felder, G. and Fivaz, J. (2010) 'More than Toys? A first assessment of voting advice applications in Switzerland', in Cedroni L. and Garzia, D. (Eds): Voting Advice Application in Europe: The State of the Art, Scriptaweb, Napoli, pp.91-123.

Lupia, A. and Philpot, T. (2005) 'Views from Inside the Net: How Websites Affect Young Adults' Political Interest', The Journal of Politics, Vol. 26, No. 4, pp.1122-1142.

Marschall, S. and Schmidt, C. (2010) 'The impact of voting indicators: the case of the German Wahl-O-Mat', in Cedroni, L. and Garzia, D. (Eds): Voting Advice Application in Europe: The State of the Art, Scriptaweb, Napoli, pp.65-90.

Price, V. and Zaller, J. (1993) 'Who gets the news? Alternative measures of news receptions and their implications for research', Public Opinion Quarterly, Vol. 57, pp.133-164.

Robinson, J.P. and Levy, M.R. (1986) The Main Source. Learning from Television News, Sage, Beverly Hills, CA.

Ruusuvirta, O. and Rosema, M. (2009) 'Do online vote selectors influence electoral participation and the direction of the vote?'. Paper presented at the European Consortium for Political Research (ECPR) General Conference, 10-12 September 2009, Potsdam, Germany.

Ruusuvirta, O. (2010) 'Much Ado About Nothing? Online Voting Applications in Finland', in Cedroni, L. and Garzia, D. (Eds): Voting Advice Application in Europe: The State of the Art, Scriptaweb, Napoli, pp.47-63.

Tichenor, P., Donohue, G. and Olien, C. (1970) 'Mass media flow and differential growth in knowledge', Public Opinion Quarterlv, Vol. 34, pp.159-170.

Vassil, K. (2011) 'Role of Self Selection in Estimating the Effects of Voting Advice Application', Paper presented at the 6th ECPR General Conference, 25-27 August, Reykjavik, Iceland.

Wall, M., Sudulich, M., Costello, R. and Leon, E. (2009) 'Picking your party online - An investigation of Ireland's first online voting advice application', Information Polity, Vol. 14, pp.203-218.

Walgrave, S., van Aelst, P. and Nuytemans, M. (2008) 'Do the Vote Test: The Electoral Effects of a Popular Vote Advice Application at the 2004 Belgian Elections', Acta Politica, Vol. 43, No. 1, pp.50-70.

Zaller, J. (1992) The Nature and Origins of Mass Opinion, Cambridge University Press, Cambridge.

\section{Notes}

1 Conflicting advices may of course come from VAAs using different methods to calculate position congruence, but these are also likely to be based on a battery of different statements. This occurs in countries where different VAAs are available, such as Finland and the Netherlands.

2 Seven lists were in competition in two of the four constituencies, to which was added one minor list in the other two. Despite the potential gains in visibility, this small list did not wish to participate to the SV.

3 The level of usage has been approximated by dividing the number of people entitled to vote by the number of SV recommendations. This result is further subdivided by two supposing that respondents request on average two profiles (one for comparing their positioning with the one of the political party and the other for measuring their positioning with the one of the candidates). 
4 Given that questions were not compulsory and that some respondents dropped in the middle of the questionnaire, the rate of response varies across variables. Since our analysis focuses on the users who could have been influenced by SV in their electoral choice, we have gathered the answers of those who used the tool from May 5th, the day following the official launching of the website, to June 7th, just before the closing time of the electoral cabins (2 PM).

5 Using the type of vote cast by the respondent in 2009 would not respect the temporal sequence needed for any causal account, as the 2009 voting act followed the decision to use or not SV during the campaign and cannot be said to influence a self-reported impact on the vote choice either. We therefore use the respondent's type of vote in the preceding election as a proxy for the degree of complexity of the vote at the individual level.

6 The dataset consisted of interviews made by phone for about one half of the respondents, the other half coming from an internet panel. Although representativeness over age, sex, work activity and geographical coverage was secured overall through sampling and weighting, those interviewed through the internet tended to be younger, better educated and more likely to be VAA users. Notice that levels of interest in the campaign, traditional media consumption and structural voting behaviour (voting for a list or for candidates) were similar for both subsamples. Level of political interest, which we can assume to be positively related to VAA usage, was even greater for the offline respondents. Nevertheless, all questions relating to the use of the internet including therefore those concerned with SV use showed significant differences between the two sub-samples. 


\section{Appendix A Operationalisation of dependent variables}

\begin{tabular}{|c|c|c|c|}
\hline Variable & Survey question & Answers & $\begin{array}{l}\text { Operationalisation and } \\
n \text { valid responses }\end{array}$ \\
\hline Usage & $\begin{array}{l}\text { During the political } \\
\text { campaign, were you } \\
\text { aware of the } \\
\text { existence of } \\
\text { smartvote.lu? }\end{array}$ & $\begin{array}{l}\text { 1. No } \\
\text { 2. Yes, but did not visit it } \\
\text { 3. Yes, but did not establish } \\
\text { a political profile } \\
\text { 4. Yes, and I established a } \\
\text { political profile } \\
\text { Do not know } \\
\text { No answer }\end{array}$ & $\begin{array}{l}\text { Category } 4 \text { was coded as } \\
1 \text { and } 1 \text { to } 3 \text { as } 0 \text { in the } \\
\text { creation of the dummy } \\
\text { variable indicating } \\
\text { usage, } n \text { valid responses } \\
=1244\end{array}$ \\
\hline Impact & $\begin{array}{l}\text { Would you say that } \\
\text { smartvote.lu } \\
\text { influenced your } \\
\text { electoral choice, } \\
\text { either by confirming } \\
\text { or changing it? }\end{array}$ & $\begin{array}{l}\text { 1. It encouraged me to vote } \\
\text { for candidates I was not } \\
\text { planning to vote } \\
\text { 2. It encouraged me to vote } \\
\text { for a party for I was not } \\
\text { planning to vote } \\
\text { 3. It strengthened my } \\
\text { choice for the political } \\
\text { party I intended to vote } \\
\text { 4. It strengthened my } \\
\text { choice for the candidates I } \\
\text { intended to vote } \\
\text { 5. It did not influence my } \\
\text { vote } \\
\text { 98. Do not know } \\
\text { 99. No answer }\end{array}$ & $\begin{array}{l}\text { Categories } 1,2,3 \text { and } 4 \\
\text { were recoded as } 1 \text { and } 5 \\
\text { as } 0 \text { in the creation of the } \\
\text { dummy variable } \\
\text { indicating impact, } n \\
\text { valid responses }=162\end{array}$ \\
\hline
\end{tabular}

\section{Appendix B Operationalisation of independent variables}

\begin{tabular}{|c|c|c|c|}
\hline Variable & Survey question & Answers & Operationalisation \\
\hline Age & $\begin{array}{l}\text { In which year were } \\
\text { you born? }\end{array}$ & Open answer & $\begin{array}{l}\text { Variable recoded into } \\
5 \text { age categories: } \\
\text { 1. } 18-24 \\
\text { 2. } 25-34 \\
\text { 3. } 35-49 \\
\text { 4. } 50-64 \\
5.65 \text { and more } \\
n \text { valid responses }= \\
1267\end{array}$ \\
\hline Gender & $\begin{array}{l}\text { Are you a man or a } \\
\text { woman? }\end{array}$ & $\begin{array}{l}\text { 1. Man } \\
\text { 2. Woman } \\
\text { 98. Do not know } \\
\text { 99. No answer }\end{array}$ & $\begin{array}{l}\text { The variable was } \\
\text { recoded with man as } 1 \\
\text { and woman as } 0, n \\
\text { valid responses }= \\
1267\end{array}$ \\
\hline Education & $\begin{array}{l}\text { What is your level of } \\
\text { education? }\end{array}$ & $\begin{array}{l}\text { 1. Primary School } \\
\text { 2. Secondary } 1 \text { st cycle } \\
\text { 3. Secondary } 2 \text { nd cycle } \\
\text { 4. Higher edu }+1 \text { to }+3 \\
\text { years } \\
\text { 5. Higher edu }+4 \text { years } \\
\text { and more } \\
\text { 98. Do not know } \\
\text { 99. No answer }\end{array}$ & $\begin{array}{l}n \text { valid responses }= \\
1162\end{array}$ \\
\hline
\end{tabular}




\section{Appendix B Operationalisation of independent variables (continued)}

\begin{tabular}{|c|c|c|c|}
\hline Variable & Survey question & Answers & Operationalisation \\
\hline $\begin{array}{l}\text { Electoral } \\
\text { constituency }\end{array}$ & & & $\begin{array}{l}\text { Recoded from place } \\
\text { of residence } \\
1 . \text { East } \\
2 . \text { North } \\
\text { 3. Centre } \\
\text { 4. South } \\
n \text { valid responses = } \\
1267\end{array}$ \\
\hline $\begin{array}{l}\text { Interest for } \\
\text { politics }\end{array}$ & $\begin{array}{l}\text { To what extent do you } \\
\text { consider yourself as } \\
\text { interested in politics? }\end{array}$ & $\begin{array}{l}\text { 1. High interest } \\
\text { 2. Average interest } \\
\text { 3. Low interest } \\
\text { 4. No interest } \\
\text { 98. Do not know } \\
\text { 99. No answer }\end{array}$ & $\begin{array}{l}\text { Categories } 3 \text { (low) } \\
\text { and } 4 \text { (no) recoded as } \\
3 \text { (not interested) } \\
n \text { valid responses }= \\
1263\end{array}$ \\
\hline $\begin{array}{l}\text { Interest for } \\
\text { political } \\
\text { campaign }\end{array}$ & $\begin{array}{l}\text { Were you interested in } \\
\text { the national electoral } \\
\text { campaign? }\end{array}$ & $\begin{array}{l}\text { 1. High interest } \\
\text { 2. Average interest } \\
\text { 3. Low interest } \\
\text { 4. No interest } \\
\text { 98. Do not know } \\
\text { 99. No answer }\end{array}$ & $\begin{array}{l}n \text { valid responses }= \\
1263\end{array}$ \\
\hline $\begin{array}{l}\text { Media } \\
\text { consumption }\end{array}$ & $\begin{array}{l}\text { How often... } \\
\text { - Did you watch an } \\
\text { electoral programme } \\
\text { on TV; } \\
\text { - Did you listen to an } \\
\text { electoral programme } \\
\text { on the radio; } \\
\text { - Did you read an } \\
\text { article in newspaper } \\
\text { (or weekly newspaper) } \\
\text {... in the last weeks } \\
\text { preceding the } \\
\text { elections? }\end{array}$ & $\begin{array}{l}\text { 1. Often } \\
\text { 2. Sometimes } \\
\text { 3. Never } \\
\text { 98. Do not know } \\
\text { 99. No answer }\end{array}$ & $\begin{array}{l}\text { The sum of values for } \\
\text { each of these three } \\
\text { traditional media } \\
\text { makes for our index } \\
\text { of media } \\
\text { consumption, with } \\
\text { therefore values } \\
\text { ranging from } 3 \text { to } 9 \\
\text { and smaller values } \\
\text { indicating high media } \\
\text { consumption; } n \text { valid } \\
\text { responses }=1188\end{array}$ \\
\hline $\begin{array}{l}\text { Preferential } \\
\text { vote } 2004\end{array}$ & $\begin{array}{l}\text { During the } 2004 \\
\text { election did you } \\
\text { express a list vote? }\end{array}$ & $\begin{array}{l}\text { 1. Yes I voted for a list } \\
\text { 2. No, I voted for the } \\
\text { candidates of a same list } \\
\text { 3. No, I voted for } \\
\text { candidates of different } \\
\text { lists } \\
\text { 98. Do not know } \\
\text { 99. No Answer }\end{array}$ & $\begin{array}{l}\text { Categories } 2 \text { and } 3 \text { are } \\
\text { recoded as } 1 \\
\text { (preferential voting) } \\
\text { and } 1 \text { as } 0 \text { (list } \\
\text { voting), } n \text { valid } \\
\text { responses }=969\end{array}$ \\
\hline $\begin{array}{l}\text { Left-right } \\
\text { positioning }\end{array}$ & $\begin{array}{l}\text { On a left-right } \\
\text { dimension where } 1 \\
\text { means « extreme left » } \\
\text { and } 10 \text { « extreme } \\
\text { right », how would you } \\
\text { position yourself? }\end{array}$ & $\begin{array}{l}\text { «left» } 1 \ldots 5 \ldots 10 \ll \text { right» } \\
\text { 97. Refusal of positioning } \\
\text { 98. Do not know } \\
\text { 99. No answer }\end{array}$ & $\begin{array}{l}n \text { valid responses }= \\
1127\end{array}$ \\
\hline
\end{tabular}

